\title{
Localized primary AL-type amyloidosis of the jejunum diagnosed by double-balloon enteroscopy
}

A 56-year-old man presented with a 5month history of upper abdominal pain and vomiting. Physical examination revealed a distended abdomen and highpitched bowel sounds. Laboratory data were within reference ranges. He underwent abdominal ultrasound and computed tomography, both of which showed significantly thickened jejunal loops. Esophagogastroduodenoscopy and ileocolonoscopy were unremarkable and tissue specimens from the stomach, duodenum, rectum, colon, and ileum showed no abnormalities on histological examination.

The patient underwent double-balloon enteroscopy, where a localized segment of ulcerated mucosa, $4 \mathrm{~cm} \times 5 \mathrm{~cm}$ in size, was seen in the proximal jejunum (Video 1). The remaining jejunum, a segment $45 \mathrm{~cm}$ in length, appeared edematous. Histological examination after hematoxylin and eosin staining (Figure $\mathbf{1} \mathbf{a}, \mathbf{b}$ ), Congo-red staining in polarized light (Figure $\mathbf{1} \mathbf{b}$, insert), anti-amyloid P-component antibody studies (Figure $\mathbf{1} \mathbf{c}$ ), and anti-lambda light chain antibody studies (Figure 1 d) revealed submucosal amyloid deposits. No amyloid deposits were found in the stomach, duodenum, ileum, colon, or rectum. Systemic amyloidosis was also excluded by bone marrow biopsy, abdominal fat-pad aspiration biopsy, and additional biopsies of the rectal mucosa. Furthermore, serum and immunoelectrophoresis and radiological investigations did not show any abnormalities. A hereditary form of amyloidosis was searched for but subsequently excluded by extensive genetic analyses of the ApoA-I gene.

We have presented an unusual case of intestinal pseudo-obstruction caused by localized primary intestinal AL-type amylodosis. Amyloid proteins are classified

\section{Video 1}

Double-balloon enteroscopy revealed a localized segment of ulcerated mucosa $(4 \mathrm{~cm} \times$ $5 \mathrm{~cm}$ ) in the proximal jejunum.
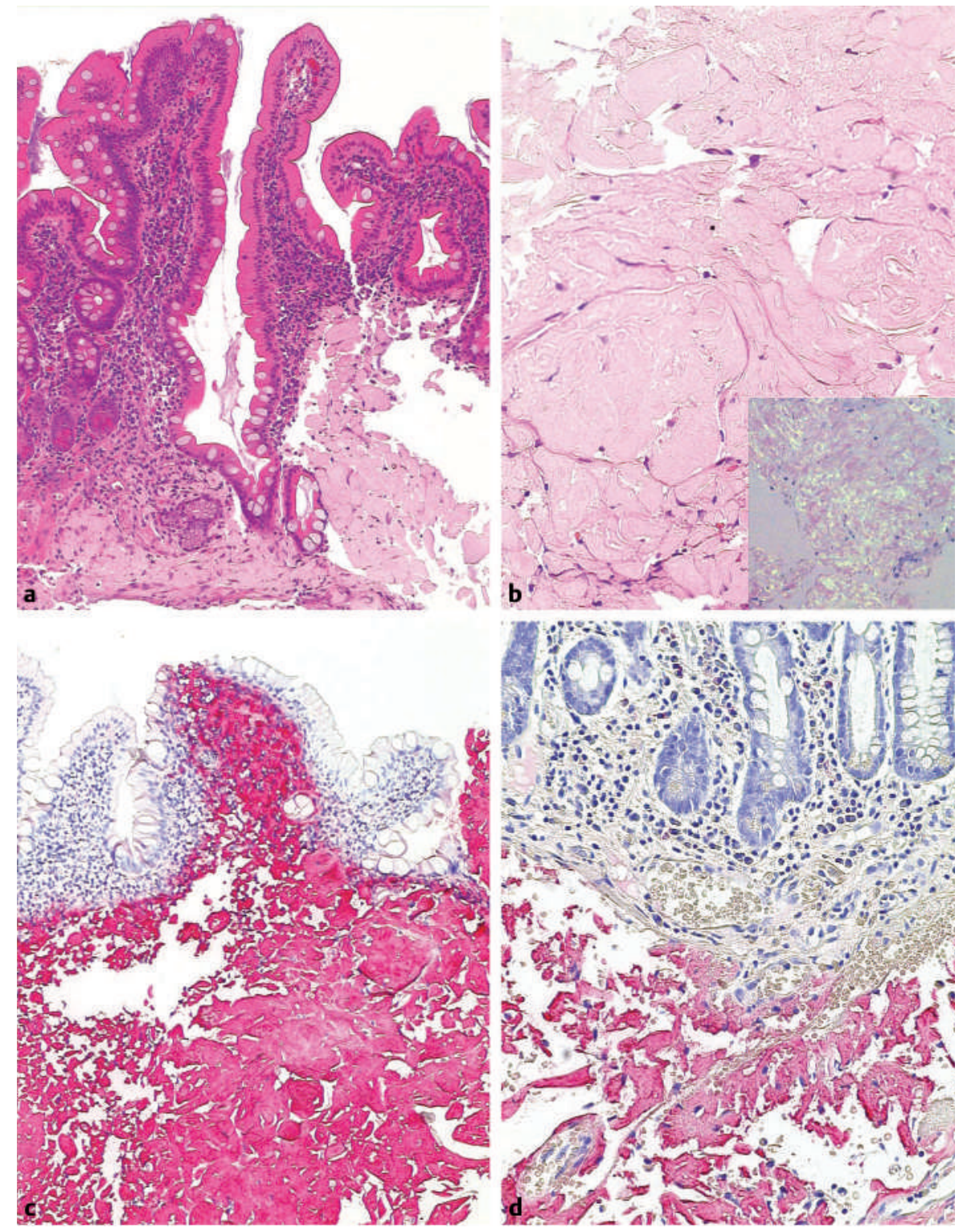

Figure 1 Histological views showing submucosal amyloid deposits after hematoxylin and eosin staining (a, b), Congo-red staining in polarized light (b, insert), anti-amyloid P-component antibody studies (c), and anti-lambda light chain antibody studies (d).

into several types: amyloid light chain protein $(\mathrm{AL})$ in primary amyloidosis, amyloid A protein (AA) in secondary amyloidosis, and transthyrein in familial amyloidosis [1]. Although gastrointestinal involvement is not uncommon in systemic amyloidosis, primary intestinal amyloidosis is extremely rare [1 -3$]$. Systemic chemotherapy with melphalan has been used to treat patients with localized amyloidosis, but this therapy has been associated with severe and life-threatening complications such as multiple bowel perforations in patients without monoclonal gammopathy [3]. Furthermore, clinical studies have demonstrated that patients with localized AL amyloidosis can remain stable over several years $[1,4]$. We therefore decided to treat our patient conserva-

DOI: $10.1055 / s-2006-944866$ 
tively, and he has remained clinically stable, without any evidence of progressive disease.

Endoscopy_UCTN_Code_CCL_1AC_2AD

Endoscopy_UCTN_Code_CCL_1AC_2AH

M. Bellutti' ${ }^{1}$ J. Weigt ${ }^{1}, K^{\prime}$. Mönkemüller ${ }^{1}$, C. Röcken ${ }^{1,2}$, G. Wieners ${ }^{3}$, F. Dombrowski ${ }^{1}$, P. Malfertheiner ${ }^{1}$

${ }^{1}$ Department of Gastroenterology, Hepatology and Infectious Diseases, Ottovon-Guericke-University, Magdeburg, Germany

${ }^{2}$ Institute of Pathology, Charité University Hospital, Berlin, Germany
${ }^{3}$ Department of Radiology, Otto-vonGuericke-University, Magdeburg, Germany.

\section{References}

${ }^{1}$ Tada S, Iida M, Yao T et al. Endoscopic features in amyloidosis of the small intestine: clinical and morphologic differences between chemical types of amyloid protein. Gastrointest Endosc 1994; 40: 45-50

2 Patel SA, al-Haddadin D, Schopp J et al. Gastrointestinal manifestations of amyloidosis: a case of diverticular perforation. Am J Gastroenterol 1993; 88: 578-582

${ }^{3}$ Schulenburg A, Kalhs P, Oberhuber G et al. Gastrointestinal perforation early after peripheral blood stem cell transplantation for AL amyloidosis. Bone Marrow Transplant 1998; 22: 293-295
${ }^{4}$ Gono T, Matsuda M, Dohi N et al. Gastroduodenal lesions in primary AL amyloidosis. Gastrointest Endosc 2002; 56: 563 -565

Corresponding author

\section{K. Mönkemüiller, M.D.}

Universitätsklinikum Magdeburg

Otto-von-Guericke University

Leipziger Straße 44

39120 Magdeburg

Germany

Fax: $\quad+49-391-6713105$

Email: Klaus.Moenkemueller@ medizin.uni-magdeburg.de 